\title{
Risk Scores in Acute Coronary Syndrome: Current Applications and Future Perspectives
}

\author{
Pedro G. M. de Barros e Silva, ${ }^{1,2,3}$ Renato D. Lopes ${ }^{1,2,4}$ \\ Brazilian Clinical Research Institute, 'São Paulo, SP-Brazil \\ Hospital Samaritano Paulista, ${ }^{2}$ São Paulo, SP - Brazil \\ Centro Universitário São Camilo, ${ }^{3}$ São Paulo, SP - Brazil \\ Duke Clinical Research Institute, Duke University School of Medicine, ${ }^{4}$ Durham, NC - USA \\ Editorial referring to the article: Validation of the Grace Risk Score to Predict In-Hospital and 6-Month Post-Discharge Mortality in Patients \\ with Acute Coronary Syndrome
}

Acute Coronary Syndrome (ACS) is the most common cause of death worldwide. ${ }^{1}$ Nevertheless, ACS represents a heterogenous group of diseases, encompassing since low-risk unstable angina (30-day mortality below $1 \%$ ), until patients with ST-elevation myocardial infarction (STEMI) and cardiogenic shock (30-day mortality around $50 \%$ ). Multivariable prediction models have been developed to classify short-term and long-term risk of these patients (Table 1). For patients with the diagnosis of ACS, the TIMI risk score and the Global Registry of Acute Coronary Events (GRACE) score have been largely used in clinical practice; the latter, despite being more complex, has shown better performance as a prognostic tool, including prognostic information not only about the acute phase but also about the risk within six months after the cardiac event. ${ }^{2}$

Neves et al., ${ }^{3}$ analyzed the performance of GRACE score in 160 patients admitted for ACS in a single center in Brazil. The results corroborate the good discrimination and calibration of GRACE score for in-hospital mortality in the Brazilian population and added information regarding its performance for sixmonth mortality. ${ }^{3}$ Despite the limited number of events and wide confidence intervals, the consistency of good discrimination and calibration of this score in different populations reinforces this model as an appropriate tool to estimate the risk of patients with ACS., ${ }^{2,3}$

\section{Keywords}

Acute Coronary Syndrome/mortality; Prognosis; Forecasting; Models, Statistical.
Once a model has shown good performance in estimating risk, it is important to determine if this information may change the clinical practice. Patients with STEMI usually receive a standard level of care and changes in the approach are made more due to complications (e.g. cardiogenic shock) than to risk scores. However, patients with non-ST elevation ACS are more heterogenous, and risk stratification models have exerted greater influence on decision making (Table 2) ${ }^{4-7}$ High-risk patients (GRACE score $>140$ ) represent a group of patients who benefit from an invasive approach in the first 24 hours, ${ }^{6,7}$ meanwhile patients at low risk may be considered for treatment outside the intensive care unit and early discharge. ${ }^{8}$ Other risk models have been developed, as the one developed by the National Cardiovascular Data Registry $\left(\mathrm{NCDR}{ }^{\circledR}\right)$, whose accuracy can be further improved by the continuous use of a very large and diverse database. ${ }^{8,9}$ In addition to the individual risk estimation of patients with ACS, these models can also be used to adjust the risk of mortality in quality-improvement registries using the observed/expected ratio, which is of great value for epidemiological analysis. ${ }^{9}$

Finally, the use of artificial intelligence as machine learning and the technique of deep learning may represent the next step in risk prediction of patients with ACS with the potential of integrating this information into the decision-making process of diagnosis and treatment. ${ }^{10}$ Until then, we should consider the traditional prediction models as a support in situations where they could provide useful information to the medical team and the patient about the risk of mortality. Finally, the result of a risk score should never be used apart from medical judgment and the combination of both represents the current good clinical practice.

Mailing Address: Renato D. Lopes

Duke Clinical Research Institute, Box 3850, 2400 Pratt Street, Durham, NC 27705 - USA.

Email: renato.lopes@dm.duke.edu. 
Table 1 - Risk scores for diagnosis and treatment of Non-ST Elevation Acute Coronary Syndromes

\begin{tabular}{|c|c|c|}
\hline Risk Score & Population & Clinical Information \\
\hline $\begin{array}{l}\text { TIMI Risk } \\
\text { Score }\end{array}$ & $\begin{array}{l}\text { Original derivation and validation studies in patients } \\
\text { with ACS; also validated in patients with chest pain (with } \\
\text { a lower performance compared to the HEART score) }\end{array}$ & $\begin{array}{l}\text { Risk at } 14 \text { days of all-cause mortality, new or recurrent myocardial } \\
\text { infarction, or severe recurrent ischemia requiring urgent } \\
\text { revascularization }\end{array}$ \\
\hline GRACE & $\begin{array}{l}\text { Original derivation and validation studies in patients } \\
\text { with ACS (better performance compared to TIMI); } \\
\text { also validated in patients with chest pain (with a lower } \\
\text { performance compared to HEART score) }\end{array}$ & $\begin{array}{l}\text { Main outcomes predicted by the GRACE score are in-hospital mortality } \\
\text { and six-month mortality + myocardial infarction }\end{array}$ \\
\hline $\begin{array}{l}\text { ACTION } \\
\text { ICU risk } \\
\text { score }\end{array}$ & $\begin{array}{l}\text { Developed in patients older than } 65 \text { years, with non-ST } \\
\text { elevation myocardial infarction and without cardiogenic } \\
\text { shock or cardiac arrest on presentation }\end{array}$ & $\begin{array}{l}\text { Predicts complications requiring intensive care - cardiac arrest, shock, } \\
\text { high-grade atrioventricular block, respiratory failure, stroke, or death } \\
\text { during the index hospitalization }\end{array}$ \\
\hline HEART score & $\begin{array}{l}\text { Adult patients presenting with symptoms suggestive of } \\
\text { ACS without new electrocardiographic changes or other } \\
\text { condition that requires admission }\end{array}$ & $\begin{array}{l}\text { Predicts six-week risk of major adverse cardiac event (acute myocardial } \\
\text { infarction, percutaneous or surgical coronary revascularization and } \\
\text { death) }\end{array}$ \\
\hline EDACS & $\begin{array}{l}\text { Adult patients with normal vital signs, chest pain } \\
\text { consistent with ACS and no ongoing chest pain or } \\
\text { crescendo angina }\end{array}$ & $\begin{array}{l}\text { Predicts 30-day major adverse cardiac events (myocardial infarction, } \\
\text { cardiac arrest, cardiogenic shock, emergency revascularization, } \\
\text { cardiovascular death, ventricular arrhythmia and/or high } \\
\text { atrioventricular block) }\end{array}$ \\
\hline ADAPT & $\begin{array}{l}\text { Suspected ACS with chest pain longer than five minutes } \\
\text { and planned observation }\end{array}$ & $\begin{array}{l}\text { Predicts 30-day major adverse cardiac events (myocardial infarction, } \\
\text { emergency revascularization, death, ventricular arrhythmia, cardiac } \\
\text { arrest, cardiogenic shock, or high-degree atrioventricular block) }\end{array}$ \\
\hline \multicolumn{3}{|c|}{$\begin{array}{l}\text { TIMI: thrombolysis in myocardial infarction; GRACE: Global Registry of Acute Coronary Events; ACTION: Acute Coronary Treatment and } \\
\text { Intervention Outcomes Network ICU risk score; HEART: history, electrocardiogram, age, risk factors and initial troponin; EDACS: Emergency } \\
\text { Department Assessment of Chest Pain Score; ADAPT: indicates 2-hour accelerated, diagnostic protocol to access patients with chest pain symptoms } \\
\text { using contemporary troponins as the only biomarkers; ACS: acute coronary syndrome. }\end{array}$} \\
\hline
\end{tabular}

Table 2 - Current recommendations for the management of patients with suspected or confirmed Non-ST elevation acute coronary syndromes based on risk-score ${ }^{4-7}$

\begin{tabular}{|c|c|c|}
\hline Guidelines & Population & Recommendations based on risk-score \\
\hline ESC & Confirmed ACS & $\begin{array}{l}\text { An early invasive strategy within } 24 \mathrm{~h} \text { is recommended in patients with a GRACE score }>140 \text { (even } \\
\text { without ECG or troponin abnormality); among patients with GRACE score }<140 \text { and without ECG or } \\
\text { troponin abnormality, the invasive strategy is not routinely recommended }\end{array}$ \\
\hline \multirow[t]{2}{*}{ BSC } & Confirmed ACS & $\begin{array}{l}\text { An early invasive strategy within } 24 \mathrm{~h} \text { is recommended in patients with a GRACE score }>140 \text { (even without } \\
\text { ECG or troponin abnormality); among patients with a GRACE score between } 109 \text { and } 140 \text {, the invasive } \\
\text { strategy is recommended within } 72 \text { hours }\end{array}$ \\
\hline & Suspected ACS & $\begin{array}{l}\text { Patients with HEART scores } \leq 3 \text { associated with negative troponin results, ECG without ischemic change, and no } \\
\text { history of coronary artery disease can be discharged from the emergency department for outpatient reassessment }\end{array}$ \\
\hline \multirow[t]{2}{*}{ ACC/AHA } & Confirmed ACS & $\begin{array}{l}\text { An early invasive strategy within } 24 \text { hours is recommended in patients with a GRACE risk score }>140 \text { (even } \\
\text { without ECG or troponin abnormality); among patients with a GRACE score between } 109 \text { and } 140 \text { (or a TIMI } \\
\text { score } \geq 2 \text { ), the invasive strategy is the standard but can be delayed until } 72 \text { hours; finally, a GRACE score < } \\
109 \text { indicates a standard non-invasive approach. }\end{array}$ \\
\hline & Suspected ACS & $\begin{array}{l}\text { Patients classified as low risk using a clinical-decision pathway (HEART, EDACS, ADAPT or NOTR) could } \\
\text { be discharged without additional testing }\end{array}$ \\
\hline \multicolumn{3}{|c|}{$\begin{array}{l}\text { BSC: Brazilian Society of Cardiology; ESC: European Society of Cardiology; ACCIAHA: American College of Cardiology/American Heart Association; ECG: } \\
\text { electrocardiographic; ADAPT: indicates 2-hour Accelerated, diagnostic protocol to access patients with chest pain symptoms using contemporary troponins as the } \\
\text { only biomarkers; EDACS: Emergency Department Acute Coronary Syndrome; HEART: pathway, history, ecg, age, risk factors, troponin; NOTR: no objective } \\
\text { testing rule; TIMI: thrombolysis in myocardial infarction. }\end{array}$} \\
\hline
\end{tabular}




\section{References}

1. Ralapanawa U, Sivakanesan R. Epidemiology and the Magnitude of Coronary Artery Disease and Acute Coronary Syndrome: A Narrative Review. J Epidemiol Glob Health. 2021 Jun;11(2):169-77. doi: 10.2991/ jegh.k.201217.001.

2. Magalhães LP, D'Ascenzo F, Biondi-Zoccai G, Moretti C, Bollati M, Omedè $\mathrm{P}$, Sciuto $\mathrm{F}$, et al. TIMI, GRACE and alternative risk scores in acute coronary syndromes: a meta-analysis of 40 derivation studies on 216,552 patients and of 42 validation studies on 31,625 patients. Contemp Clin Trials 2012; 33(3):507-14.:1-22. doi: 10.1016/j. cct.2012.01.001.

3. Neves VB, Roman RM, Vendruscolo T, Heineck G, Mattos CA, Mattos EI, et al. Validation of the Grace Risk Score to Predict In-Hospital and 6-Month Post-Discharge Mortality in Patients with Acute Coronary Syndrome. Int J Cardiovasc Sci. 2022; 35(2):174-180. Doi: https://doi. org/10.36660/ijcs.20210019.

4. Amsterdam EA, Wenger NK, Brindis RG, Casey DE Jr, Ganiats TG, Holmes DR Jr, et al. 2014 AHA/ACC Guideline for the Management of Patients with Non-ST-Elevation Acute Coronary Syndromes: a report of the American College of Cardiology/American Heart Association Task Force on Practice Guidelines. J Am Coll Cardiol. 2014 Dec 23;64(24):e139-e228. https://doi.org/10.36660/ijcs.20210019

5. Collet JP, Thiele H, Barbato E, Barthélémy O, Bauersachs J, Bhatt DL, et al; ESC Scientific Document Group. 2020 ESC Guidelines for the management of acute coronary syndromes in patients presenting without persistent ST-segment elevation. Eur Heart J. 2021 Apr 7;42(14):1289-367. doi: 10.1093/eurheartj/ehaa575.

6. Nicolau JC, Feitosa-Filho G, Petriz JL, Furtado RHM, Précoma DB, Lemke W, et al. Diretrizes da Sociedade Brasileira de Cardiologia sobre Angina Instável e Infarto Agudo do Miocárdio sem Supradesnível do Segmento ST -2021. Arq Bras Cardiol. 2021;117(1):181-264. doi: 10.36660/abc.20210180.

7. Gulati M, Levy PD, Mukherjee D, Amsterdam E, Bhatt DL, Birtcher KK, et al. 2021 AHA/ACC/ASE/CHEST/SAEM/SCCT/SCMR Guideline for the Evaluation and Diagnosis of Chest Pain: A Report of the American College of Cardiology/American Heart Association Joint Committee on Clinical Practice Guidelines. Circulation. 2021 Nov 30;144(22):e368-e454. doi: 10.1161/CIR.0000000000001029.

8. Guimarães PO, Sampaio MC, Malafaia FL, Lopes RD, Fanaroff AC, de Barros E Silva PGM, et al. Clinical outcomes and need for intensive care after non-ST-segment-elevation myocardial infarction. Eur J Intern Med. 2020 Jun;76:58-63. doi: 10.1016/j.ejim.2020.02.008.

9. de Barros E Silva PGM, Ribeiro HB, Lopes RD, Macedo TA, Conejo F, do Amaral Baruzzi AC, et al. Improvement in quality indicators using NCDR® registries: First international experience. Int J Cardiol. 2018; Sep 15;267:13-5. https://doi.org/10.36660/abc.20190885

10. Wang H, Zu Q, Chen J, Yang Z, Ahmed MA. Application of Artificial Intelligence in Acute Coronary Syndrome: A Brief Literature Review. Adv Ther. 2021 Oct;38(10):5078-86. DOI: 10.1007/s12325-021-01908-2] [Reference Citation Analysis] 